\title{
POST-OPERATIVE EYE MASSAGE IN CASES OF GLAUCOMA*†
}

BY

\author{
T. G. WYNNE PARRY
}

Bangor

THE importance of regular massage after filtration operations for glaucoma is stressed by most authorities. The difficulty of implementing this advice is great in most cases, since few patients have the touch and understanding to carry out their instructions properly. In elderly patients with arthritic finger joints and a defective sense of touch, etc., to advise massage may mean endangering the eye. To avoid such risks and to make it easy for the most unintelligent to apply regular massage a simple and cheap appliancet has been devised, which has given satisfaction during the last few months.

\section{Construction}

The appliance consists of two rubber bulbs connected by a length of tubing. One bulb is of soft rubber capable of easy dilatation; the other is of stouter construction and when this second bulb is squeezed and released, the soft bulb dilates and contracts. The soft bulb is held in a shallow cup of light metal, and a small three-way tap is fixed in the tubing. The illustration will make these details plain.

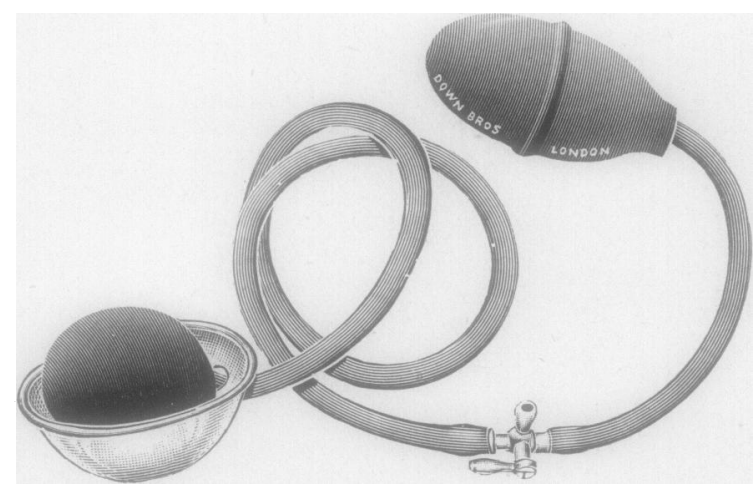

Figure.

\section{Method of Application}

To use the apparatus, the soft bulb is held firmly in one hand by means of the shallow metal cup and is placed against the closed eye, and the harder

* Received for publication September 8, 1952.

+ It is manufactured by Messrs. Down Bros. and Mayer and Phelps, Ltd., 32-34, New Cavendish St., London, W.1., who have been most helpful. 
bulb is then squeezed and released in the other hand with a regular rhythm. In the tests so far made the " massage " (for want of a better term) has been applied with the eyes closed and turned up and then looking right and then left, to avoid pressure on filtering area. It has been found that in most cases the ocular tension is markedly reduced by about twenty to forty inflations; in other cases, the inflations may have to be repeated up to 120 times or more. Many unoperated glaucoma cases also respond well.

Occasionally the softer bulb tends to collapse, probably owing to some leakage of air from the system. To remedy this the small tap is opened to put the closed system in communication with the atmosphere, and the bulb will then immediately fill again.

There has not been much time to carry out extended experiment and tabulation, but the beneficial effect on ocular tension is undoubted. Three of my colleagues have very kindly given the appliance a trial for some weeks and their results are in agreement with mine. It is hoped that this simple appliance may contribute a little towards successful results in filtration operations. 